\title{
Hospitalized patients' pain experience before and after the introduction of a nurse-based pain management programme: a separate sample pre and post study
}

\author{
Gugsa Nemera Germossa ${ }^{1,2^{*}}$ (D), Ragnhild Helles $\varnothing^{2}$ and Ingeborg Strømseng Sjetne ${ }^{3}$
}

\begin{abstract}
Background: Many patients suffer from unrelieved pain in hospital settings. Nurses have a pivotal role in pain management. Hence, a nurse-based pain management programme may influence how hospitalized patients experience pain. In this study we investigated hospitalized patients' experience of pain before and after the introduction of a two-component nurse-based pain management programme.
\end{abstract}

Methods: A quasi-experimental design with a separate sample pretest-posttest approach was conducted on a convenience sample of 845 patients (Survey 1: $N=282$; Survey 2: $N=283$; Survey 3: $N=280$ ) admitted to the four inpatient units (medical, surgical, maternity, and gynecology) of a university medical center. Data were collected at baseline, before the intervention six weeks after pain management education, and finally immediately after four months of rounding using an interviewer-administered questionnaire adopted from a Brief Pain Inventory and the American Pain Society Patient Outcome Questionnaire.

Results: All the samples had similar sociocultural backgrounds. The proportion of patients who reported average moderate and severe pain intensity in the last $24 \mathrm{~h}$ were $68.8 \%$ in Survey 1,72.8\% in Survey 2 and then dropped to $48.53 \%$ in Survey 3 whereas those who reported moderate and severe pain intensity at the time of interview were $53.9 \%$ in Survey $1,57.1 \%$ in Survey 2 and then dropped to $37.1 \%$ in Survey 3 . The mean pain interference with the physical and emotional function was generally reduced across the surveys after the introduction of the nurse-based pain management programme. These reductions were statistically significant with $p<0.05$.

Conclusions: Though the survey findings must be taken with caution, they demonstrate that the nurse-based pain management programme positively influenced patient-reported pain intensity and functional interference at the university medical center. This shows the potential clinical importance of the programme for hospitalized patients.

Keywords: Pain management, Education, Nursing care, Inpatients

\footnotetext{
*Correspondence: gugsanemer@gmail.com; g.n.germossa@studmed.uio.no

${ }^{1}$ School of Nursing and Midwifery, Jimma University Institute of Health

Sciences, Jimma University, 378 Jimma, Ethiopia

${ }^{2}$ Department of Nursing Sciences Institute of Health and Society Faculty of

Medicine, University of Oslo, Oslo, Norway

Full list of author information is available at the end of the article
}

(c) The Author(s). 2019 Open Access This article is distributed under the terms of the Creative Commons Attribution 4.0 International License (http://creativecommons.org/licenses/by/4.0/), which permits unrestricted use, distribution, and reproduction in any medium, provided you give appropriate credit to the original author(s) and the source, provide a link to the Creative Commons license, and indicate if changes were made. The Creative Commons Public Domain Dedication waiver (http://creativecommons.org/publicdomain/zero/1.0/) applies to the data made available in this article, unless otherwise stated. 


\section{Introduction}

The occurrence of pain symptoms is one of the primary reasons to seek healthcare in the general population. Pain is often distressing for patients if not adequately managed [1-3] and may lead to anxiety, depression, fatigue, a desire for death, escalated pain, poor quality of life, limitations in Activities of Daily Living (ADLs), poor compliance with treatment, and prolonged hospital stays [3-6].

Despite the availability of effective therapies, many patients continue to suffer from unrelieved pain in hospital settings [7]. As a result, international pain organizations have called for a strategy to improve pain management practices [2] that include pain assessment, appropriate use of analgesics, and proactive responses [8].

Even though pain management is the responsibility of every healthcare provider, it is the primary role of nurses. Nursing is an important caregiving situation, and pain management is an integral part of the practice of nursing. Left untreated, pain is considered professional misconduct or a violation of fundamental human rights [1-3]. Despite this, inadequately managed pain is highly prevalent, particularly in Ethiopian hospitals, due to a lack of appropriate care [9]. For example, it was reported that $80.1 \%$ of surgical patients at Jimma University Hospital were inadequately managed for pain [10]. Studies have revealed that a number of factors contribute to inadequate pain management: provider negligence, fragmented care, nurses' lack of adequate knowledge of and attitudes towards pain, and the lack of a system that engages, empowers and motivates nurses [11-13].

Prior studies related to pain management were mainly focused on the prevalence of pain [14-16], the effectiveness of the educational programme [17-20], analgesic use [21], nonpharmacological therapies, and the description of interventions related to cancer and HIV pain [22, 23]. However, a study on the effectiveness of a nurse-led pain management intervention for patients with chronic pain that employed cognitive behavioral treatment showed an improvement in the reduction of pain intensity [24]. Yet, to our knowledge, there are no studies that investigate hospital patients' pain intensity and interference across various units before and after the introduction of a nursebased pain management programme. Thus, building on the existing system, we introduced a nurse-based pain management programme in an Ethiopian university hospital. The programme consists of intensive in-service nurse education aimed to enhance nurses' knowledge of and attitudes towards pain [25], and a rounding routine to ensure the systematic monitoring of patients' pain. Ultimately, the goal was to improve pain treatment practice and to measure the effectiveness of the programme on patients' pain experiences on three occasions. The aim of this study was, therefore, to investigate the level of patient-reported pain experiences before and after the introduction of a two-component nurse-based pain management programme.

\section{Methods \\ Study design and setting}

A quasi-experimental design with a separate sample pretest-posttest approach was conducted at Jimma University Medical Center (JUMC) from 1 September 2016, to 15 July 2017.

\section{Participants}

A convenience sample of 845 patients (Survey 1: $N=$ 282; Survey 2: $N=283$; Survey 3: $N=280$ ) was invited to participate in this study. All patients who were admitted to the four inpatient units at the hospital (medical, surgical, maternity, and gynecology wards) were included if they filled the inclusion criteria. Patients had to have been hospitalized for at least $24 \mathrm{~h}$, age $\geq 18$ years, and have no known hearing impairment. Initial contact with patients was made through the ward's head nurse or shifts leader. Participation in the study was voluntary. None of the patients approached declined participation.

\section{A nurse-based pain management programme}

A nurse-based pain management programme is an intervention comprised of two components: education (to enhance nurses' knowledge of and attitude towards pain) and organizational elements (to ensure the systematic monitoring of patients' pain), with the goal of improving pain treatment. In the educational component, we provided two days of intensive in-service pain management training ( $16 \mathrm{~h}$ of face-to-face training), take-home reading assignments (self-learning), and refresher training four weeks later $(8 \mathrm{~h})$ for all nurses in the units. The education programme was arranged in groups and completed between 1 October and 15 November 2016. Each group was comprised of 30-40 nurses. The education sessions were delivered as per the pain management protocol developed by the research team, which was based on Ethiopia's Federal Ministry of Health (FMOH) pain management guidelines [11] the World Health Organization's (WHO) guidelines for pain management $[26,27]$. Following the education programme, we introduced the second component, a rounding programme to educate staff nurses and nurse leaders in patient goaloriented pain management [28]. The rounding programme consisted of an engagement orientation on how to organize and conduct rounding. The rounding programme lasted one day $(8 \mathrm{~h})$ for all staff nurses and a half day (four hours) for nurse leaders and supervisors. The content of the orientation included regular pain assessment using the numerical rating scale (NRS), charting in rounding logs when it was necessary to consult the physician, scripted dialogue with the patients, 
and how to assess patients using the four Ps: presence, pain, position, and personal needs. Rounding was structured in such a way that nursing directors, head nurses, and staff nurses proactively made regular and consistent visits to patients and performed scheduled tasks focused on pain management. When nurses visited patients during rounds, they introduced themselves and read the following script in either the Afaan Oromo or Amharic language (according to the patient's language preference): "We are going to do everything we can to help keep your pain under control. Your pain management is our number-one priority. Given your (condition, history, diagnosis, status), we may not be able to keep your pain level at zero. However, we will work very hard with you to keep you as comfortable as possible" [4]. Staff nurses made subsequent visits every $2 \mathrm{~h}$ during the day $(8,00 \mathrm{am}-8,00$ $\mathrm{pm})$ and every $4 \mathrm{~h}$ at night $(10,00 \mathrm{pm}-6,00 \mathrm{am})$. During each visit, nurses assured patients of their availability and informed patients when they would return, asked patients to rate their pain levels, and recorded it in the pain log. If necessary, they repositioned the patient and checked for personal needs (toileting, getting out of bed, water).

More specifically, staff nurses systematically assessed every patient admitted to the four units up to ten times (every $2 \mathrm{~h}$ during the day and every $4 \mathrm{~h}$ during the night) in a 24-h period. Unless the patient was unconscious, sleeping or the bed was empty, the pain level was self-rated using the NRS and recorded in the pain log by the nurse. After each pain assessment, the nurse decided if the patient required a change in pain treatment regimen in collaboration with the treating physician, using the $\mathrm{WHO}$ pain ladder framework. Based on the collaborative decision, the nurse administered adjusted pain medication by the clock. "By the clock" means that the patient would be given analgesics regularly at a fixed interval of time-based on the known pharmacokinetics of the drug in use and that the next dose of analgesics would be adjusted before the effect of the previous dose had fully worn off. The rounding log was kept easily accessible for the healthcare provider's review. In addition, nurses participated in the multidisciplinary team rounds and shared patient pain information.

Leadership rounding was performed daily by head nurses or clinical leaders (team leaders) and weekly by nursing directors. The leaders' role was to motivate, facilitate, and provide positive feedback to the nurses. In addition, the head nurse-led weekly staff nurse discussions, and the nursing director led monthly discussions for head nurses and supervisors. Compliance with the rounding protocol was monitored twice weekly by nurse supervisors, using a review of the rounding $\log$ and discussion minutes.

\section{Measurements}

Pain intensity and interference are regarded as reliable parameters to measure patients' experiences of pain [29].
To measure the patient pain experience, we used a tool consisting of 18 items adapted from the Brief Pain Inventory (BPI) [30] and the American Pain Society Pain Outcome Questionnaire-Revised (APS-POQ-R) [31]. Items that were used to measure pain prevalence in the last $24 \mathrm{~h}$ (one item), pain treatment information (two items), and pain intensity (four items) were adopted from the BPI. Pain intensity/severity was measured on the 11 -points NRS (from $0=$ no pain to $10=$ worst possible pain) with four scores: for pain present at the time of interview ("right now"), pain at its worst during the last $24 \mathrm{~h}$, pain at its least over the past $24 \mathrm{~h}$, and pain on average over the past $24 \mathrm{~h}$. A pain severity/intensity level less than 4 is regarded as mild pain, greater than or equal to 4 and less than or equal to 6 is moderate, and greater than or equal to 7 is severe pain on the 0 to 10 NRS [1]. Eleven items used to measure pain interference (six items for physical functions and four items for emotional functions) were adopted from the APS-POQ-R. Patients were asked to rate their pain's interference with physical functions such as activity in bed (sitting up, turning in bed), activity out of bed (walking, standing, squatting, use of wheelchair, dressing, etc.), deep breathing and coughing exercise (postoperative patients), sleeping (falling asleep, staying asleep), and relationships with others as well as interference with emotional function, in this case mood disturbance (anxious, depressed, frightened, feeling helpless). All functions were measured on an 11-point rating scale $(0=$ no interference, $10=$ complete interference). Scores less than 3 indicate mild, greater than or equal to 3 and less than or equal to 4 indicate moderate, and greater than 4 indicate severe interference [1].

The tool was initially translated by healthcare professionals to Afaan Oromo and Amharic; linguistics and non-health care professionals then retranslated back to English. Then, all the translators came together to discuss the translated items. To check how each item was understood, a cognitive interview was conducted with five people of varying backgrounds [32]. Finally, the tool was tested on 35 patients from various units to clarify words and the sequence of the items. We have also collected information on admission unit (the type of unit), sociodemographic characteristics (age, sex, address), and socioeconomic variables (educational level, occupation, monthly income). The principal investigator collected the completed questionnaires from the data collectors daily and stored them in locked cabinets.

\section{Data collection procedure}

Data was first collected at baseline (Survey 1), again six weeks after the educational programme (Survey 2), followed by a third survey immediately after four months of rounding (Survey 3 ). The data were collected by trained 
nurses through a structured face-to-face interview that lasted approximately $40-45 \mathrm{~min}$.

\section{Data analysis}

All surveys were assessed for missing or incomplete data before being analyzed (survey 1: 26, survey 2: 24, survey 3: 13). Data were analyzed using Statistical Package for the Social Sciences (SPSS) version 20.1 (IBM SPSS Statistics for Windows, Armonk, NY). Descriptive statistics (i.e., mean, standard deviations, range, frequency) were calculated for patient characteristics (age, income), pain severity, and interference response items. Reduction in the sample means score was calculated by subtracting the mean value of survey 3 from the mean value of survey 1 , dividing it by the survey 1 value, and multiplying by 100 . Differences between the mean pain intensity and interference scores at baseline (Survey 1), six weeks after the in-service educational program (Survey 2), and immediately after four months of rounding (Survey 3 ) were analyzed using a one-way Analysis of Variance (ANOVA) with a post-hoc Bonferroni test. The significant differences between the surveys were declared at $p \leq 0.05$.

\section{Results}

\section{Sample characteristics}

Of the 845 eligible patients, 782 patients' complete responses from (Survey 1: $N=256$; Survey 2: $N=259$; Survey 3: $N=267$ ) were analyzed (Fig. 1 ). There were no differences in the mean ages of the respondents (Survey 1: mean age $=38.1(\mathrm{SD} \pm 16.2)$; Survey $2:$ mean age $=$ 37.4 $(\mathrm{SD} \pm 15.2)$; Survey 3: mean age $=37.9(\mathrm{SD} \pm 5.2)$ ). Though the percentage of missing values for income was high (30.4\% for Survey 1, 42.8\% for Survey 2, and 60\% for Survey 3), the median monthly income in Ethiopian currency was 1000 birr for all surveys: the interquartile range was 1054 birr for Survey 1, 1500 birr for Survey 2, and 1500 birr for Survey 3. When converted to US currency, $50 \%$ of respondents earned just over one US dollar per day ( 1 US dollar $\approx 27.91$ Ethiopian birr). There were no statistically significant differences in sociocultural characteristics between the three samples, and there were no reports of new disease epidemics in the area. As shown in Table 1, except for the unit of admission, there was no difference in the distribution of the sample characteristics by survey period.

\section{Pain treatment}

Most patients received anti-pain medication intramuscularly and/or intravenously. In Survey 2, the proportion of patients treated with a pharmacological agent increased by $14.1 \%$ compared with Survey 1, by $4.8 \%$ in Survey 3 compared with Survey 2, and by $19.7 \%$ in Survey 3 compared with Survey 1. Prayers, massage, and cold or hot application were commonly reported nonpharmacological pain therapies provided by patient attendants (Table 2).

\section{Pain intensity}

Table 3 shows the samples' mean pain intensity in the first, second, and third surveys. The results of all three surveys show that patients generally had moderate to severe pain. However, the mean pain intensity levels were generally reduced across the survey period. This reduction was statistically significant between the second and first survey as well as between the third and first survey for the worst pain, least pain, and pain "right now". Reduction in the samples' mean scores for pain

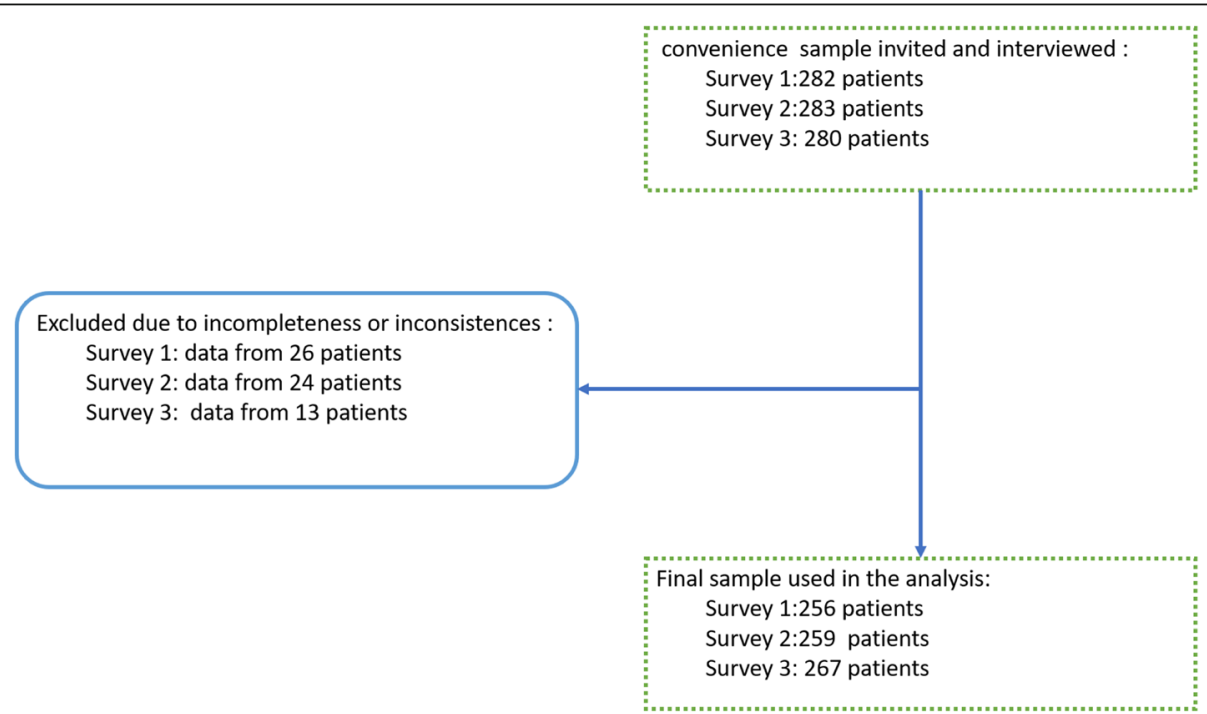

Fig. 1 Schematic representation of subject recruitment. Data was collected three times from three different samples. First at baseline (Survey 1), again six weeks after the educational programme (Survey 2), and for the third time immediately after the four months of rounding (Survey 3 ) 
Table 1 Sample characteristics

\begin{tabular}{|c|c|c|c|c|c|c|}
\hline \multirow[t]{2}{*}{ Sample characteristics } & \multirow{2}{*}{$\begin{array}{l}\text { Survey } 1 \\
\text { Number } \\
(\%)\end{array}$} & \multirow{2}{*}{$\begin{array}{l}\text { Survey } 2 \\
\text { Number } \\
(\%)\end{array}$} & \multirow{2}{*}{$\begin{array}{l}\text { Survey } 3 \\
\text { Number } \\
(\%)\end{array}$} & \multicolumn{3}{|l|}{$p$-value ${ }^{a}$} \\
\hline & & & & $\begin{array}{l}\text { Survey } 1 \text { vs } \\
\text { Survey } 2\end{array}$ & $\begin{array}{l}\text { Survey } 1 \text { vs } \\
\text { Survey } 3\end{array}$ & $\begin{array}{l}\text { Survey } 2 \text { vs } \\
\text { Survey } 3\end{array}$ \\
\hline Gender & $(N=256)$ & $(N=259)$ & $(N=267)$ & & & \\
\hline Male & $125(48.8)$ & $139(53.7)$ & $134(50.2)$ & 0.274 & 0.757 & 0.426 \\
\hline Female & $131(51.2)$ & $120(46.3)$ & $133(49.1)$ & & & \\
\hline Address & $(N=247)$ & $(N=237)$ & $(N=263)$ & & & \\
\hline Urban & $169(68.4)$ & $164(69.2)$ & $173(65.8)$ & 0.808 & 0.528 & 0.418 \\
\hline Rural & 78 (31.6) & $73(30.8)$ & $90(34.2)$ & & & \\
\hline Educational level & $(N=253)$ & $(N=253)$ & $(N=266)$ & & & \\
\hline Had no formal education & $151(59.7)$ & $150(59.3)$ & $171(64.3)$ & 0.928 & 0.282 & 0.243 \\
\hline Had formal education & $102(40.3)$ & $103(40.7)$ & $95(35.7)$ & & & \\
\hline Occupation & $(N=253)$ & $(N=253)$ & $(N=266)$ & & & \\
\hline Farmer & $151(59.9)$ & $133(51.8)$ & $148(55.4)$ & 0.168 & 0.366 & 0.074 \\
\hline Government employee & $28(11.1)$ & $44(17.1)$ & $29(10.9)$ & & & \\
\hline Self-employed & $36(14.3)$ & $41(16.0)$ & $35(13.1)$ & & & \\
\hline Unemployed & $37(14.7)$ & $39(15.2)$ & $55(20.6)$ & & & \\
\hline Unit of admission & $(N=256)$ & $(N=259)$ & $(N=267)$ & & & \\
\hline Surgical & $133(52.0)$ & $104(40.2)$ & $98(36.7)$ & 0.008 & 0.001 & 0.831 \\
\hline Medical & 86 (33.6) & $89(34.4)$ & 101 (37.8) & & & \\
\hline Gynaecology & $20(7.8)$ & $34(13.1)$ & $34(12.7)$ & & & \\
\hline Maternity & $17(6.6)$ & $32(12.4)$ & 34 (12.7) & & & \\
\hline
\end{tabular}

${ }^{a}$ Critical value when proportions were compared using WINPEPI, using a comparison of two independent samples

intensity at its average during the last $24 \mathrm{~h}$ was statistically significant between all three surveys. In the third survey, the sample means' pain intensity was reduced by $27.6 \%$ at for pain at its worst, $23.8 \%$ for pain at its least, $25.5 \%$ for pain at its average over the last $24 \mathrm{~h}$, and current pain by $29.3 \%$ compared with Survey 1 . Even though the proportion of patients who reported pain in the last $24 \mathrm{~h}$ generally decreased after the intervention, the proportion of patients who experienced pain in the last $24 \mathrm{~h}$ in the second survey was slightly higher (94.5\%) than in the first survey (93\%). However, immediately after four months of rounding (in the third survey), the proportion was reduced to $87.3 \%$.

The results of all three surveys show that patients generally had moderate to severe pain when asked for "average pain in the last 24 hours" and "pain right now". However, as indicated in Table 4, the proportion of patients with severe pain was generally reduced across the survey period.

Table 2 Patient-reported pain treatment method and route of pain medication administration

\begin{tabular}{llll}
\hline Pain treatment & Survey $1(N=256)$ Number $(\%)$ & Survey $2(N=259)$ Number $(\%)$ & Survey $3(N=267)$ Number $(\%)$ \\
\hline $\begin{array}{l}\text { Method of treatment } \\
\text { Pharmacological }\end{array}$ & $161(62.9)$ & $186(71.8)$ & $201(75.3)$ \\
Non- pharmacological & $13(5.1)$ & $8(3.1)$ & $4(1.5)$ \\
Mixed & $72(28.1)$ & $57(22.0)$ & $56(21.0)$ \\
None & $8(3.1)$ & $8(3.1)$ & $6(2.2)$ \\
Missed data & $2(0.8)$ & 0 & 0 \\
Route of pain medication & & $124(51.0)$ & $137(53.7)$ \\
Parenteral (IM/IV) & $105(45.1)$ & $54(22.2)$ & $44(17.3)$ \\
Oral & $44(18.9)$ & $65(26.7)$ & $74(29.0)$ \\
Both & $84(36.1)$ & & \\
\hline
\end{tabular}


Table 3 The sample mean pain intensity scores

\begin{tabular}{|c|c|c|c|c|c|c|}
\hline \multirow[t]{2}{*}{ Pain intensity } & \multirow{2}{*}{$\begin{array}{l}\text { Survey } \\
1 \text { Mean } \\
\text { (SD) }\end{array}$} & \multirow{2}{*}{$\begin{array}{l}\text { Survey } \\
2 \text { Mean } \\
\text { (SD) }\end{array}$} & \multirow{2}{*}{$\begin{array}{l}\text { Survey } \\
3 \text { Mean } \\
\text { (SD) }\end{array}$} & \multicolumn{3}{|l|}{$p$-value ${ }^{a}$} \\
\hline & & & & Survey 1 vs. Survey 2 & Survey 1 vs. Survey 3 & Survey 2 vs. Survey 3 \\
\hline Your pain at its worst in the last $24 \mathrm{~h}$ & $5.8(2.6)$ & $5.3(2.0)$ & $4.2(1.8)$ & 0.069 & 0.000 & 0.001 \\
\hline Your pain at its least in the last $24 \mathrm{~h}$ & $4.2(2.4)$ & $4.0(2.0)$ & $3.2(1.6)$ & 0.627 & 0.000 & 0.001 \\
\hline Your pain on average in the last $24 \mathrm{~h}$ & $4.7(2.2)$ & $4.2(1.2)$ & $3.5(1.4)$ & 0.008 & 0.000 & 0.001 \\
\hline How much pain you have right now & $4.1(2.8)$ & $3.8(2.0)$ & $2.9(1.9)$ & 0.387 & 0.000 & 0.001 \\
\hline
\end{tabular}

a $P$-value using one-way ANOVA with post hoc test

\section{Pain interference}

In all three surveys, the score for the mean pain interference scales indicates moderate to severe interference with both physical and emotional functions. As shown in Table 4, only minor differences were observed in the level of patient-reported pain interference between Survey 1 and Survey 2. Apart from activities out of bed, a statistically significant reduction in pain interference with physical functions was observed between both the first and third surveys and the second and third surveys. On the other hand, the mean level interference with relationship and negative feelings (anxious, depressed, frightened, and helpless) significantly decreased in Survey 2 and Survey 3 compared with Survey 1. However, the reduction in feeling helpless occurred between the third and second surveys (Table 5).

\section{Discussion}

In this study, we investigated patients' pain experiences before and after the introduction of a nurse-based pain management intervention. The goal of the intervention was to improve pain treatment practices and provide timely and optimal treatment. The overall findings show that patients reported less pain intensity as well as functional interference after the intervention. The mean pain intensity level at its worst, least, and on average in the last $24 \mathrm{~h}$ and at the time of survey ("right now") was generally reduced in the third survey immediately after four months of rounding. On the other hand, the proportion of patients who reported pain in the last $24 \mathrm{~h}$ was reduced from 93\% in Survey 1 to $87.3 \%$ in Survey 3. Similarly, the mean pain interference with physical and affective functions was also greatly reduced. These reductions can be attributed to better pain management following the intervention. This could have prevented patients from severe discomfort and impaired physiological homeostasis such as depressed mood, fatigue, limitation of ADLs, and anxiety [3-6, 33]. The intervention is in line with the WHO [34], the APS [8], the Joint Commission on Accreditation of Healthcare Organizations (JCAHO) [35], the (FMOH) [11] guidelines. These guidelines recommend regular pain assessment and appropriate use of pain therapies.

Pain intensity and interference with function are important parameters in the evaluation of the effectiveness of pain management interventions on the part of patients [29, 36] and patient responses to pain-producing medical procedures [37]. The findings of the current study show the degree to which patients received the essential elements of pain management: pain assessment, aligning analgesics with the patient's pain level, and consistent monitoring. Compared with the results in Survey 1, pain intensity level (at present, at least, at worst, and on average), and the level of pain interference with physical and emotional function significantly decreased in the second and third surveys. Though there are no similar studies with which to compare, the findings are in accordance with results from other earlier, related studies, including nurse-based pain management programmes [24], pain educational programmes [17-20], and

Table 4 The proportion of patients with mild, moderate and severe pain when asked for average pain in the last $24 \mathrm{~h}$ and pain "right now" by survey period

\begin{tabular}{|c|c|c|c|c|}
\hline Severity of pain & & Survey 1 & Survey2 & Survey 3 \\
\hline \multirow[t]{4}{*}{ Average pain } & $\mathrm{N}$ & 237 & 247 & 233 \\
\hline & Mild & 31.2 & 27.1 & 51.5 \\
\hline & Moderate & 47.3 & 69.2 & 46.4 \\
\hline & Severe & 21.5 & 3.6 & 2.1 \\
\hline \multirow{4}{*}{$\begin{array}{l}\text { Pain at the time } \\
\text { of the interview ("right now") }\end{array}$} & $\mathrm{N}$ & 256 & 259 & 267 \\
\hline & Mild & 46.1 & 42.9 & 62.9 \\
\hline & Moderate & 32.4 & 49.4 & 34.5 \\
\hline & Severe & 21.5 & 7.7 & 2.6 \\
\hline
\end{tabular}


Table 5 The samples' mean scores on pain interference with physical and emotional function

\begin{tabular}{|c|c|c|c|c|c|c|}
\hline \multirow[t]{2}{*}{ Pain interference with } & \multirow{2}{*}{$\begin{array}{l}\text { Survey } \\
1 \text { Mean } \\
\text { (SD) }\end{array}$} & \multirow{2}{*}{$\begin{array}{l}\text { Survey } \\
2 \text { Mean } \\
\text { (SD) }\end{array}$} & \multirow{2}{*}{$\begin{array}{l}\text { Survey } \\
3 \text { Mean } \\
\text { (SD) }\end{array}$} & \multicolumn{3}{|l|}{$p$-value } \\
\hline & & & & Survey 1 vs. Survey 2 & Survey 1 vs. Survey 3 & Survey 2 vs. Survey 3 \\
\hline \multicolumn{7}{|l|}{ Physical functions } \\
\hline Activity in bed & $4.6(3.4)$ & $4.6(3.1)$ & $3.9(2.8)$ & 1.000 & 0.026 & 0.021 \\
\hline Activities out of bed & $5.0(3.6)$ & $4.9(3.1)$ & $4.4(3.1)$ & 1.000 & 0.073 & 0.170 \\
\hline Falling asleep & $4.3(3.1)$ & $4.3(2.8)$ & $3.5(3.1)$ & 1.000 & 0.014 & 0.015 \\
\hline Staying asleep & $4.3(3.1)$ & $4.1(3.0)$ & $3.7(3.2)$ & 1.000 & 0.044 & 0.379 \\
\hline Deep breathing and coughing & $3.4(3.2)$ & $3.1(3.4)$ & $1.2(2.2)$ & 1.000 & 0.000 & 0.001 \\
\hline \multicolumn{7}{|l|}{ Emotional functions } \\
\hline Relationships with others & $3.6(3.2)$ & $3.0(3.1)$ & $2.8(2.9)$ & 0.089 & 0.010 & 1.000 \\
\hline Anxious & $5.4(3.1)$ & $5.3(2.7)$ & $4.3(3.0)$ & 1.000 & 0.000 & 0.001 \\
\hline Emotion (Depression) & $5.2(3.0)$ & $5.2(2.7)$ & $4.3(3.1)$ & 1.000 & 0.001 & 0.003 \\
\hline Frightened & $4.9(3.2)$ & $5.0(3.0)$ & $4.1(3.4)$ & 1.000 & 0.019 & 0.011 \\
\hline Helplessness & $3.7(3.4)$ & $3.8(3.3)$ & $3.1(3.9)$ & 1.000 & 0.142 & 0.036 \\
\hline
\end{tabular}

${ }^{a} P$-value using one-way ANOVA with post hoc test

postoperative pain management programmes $[22,23]$ on chronic pain and its interference with physical and emotional function.

Even though the current study showed a significant positive impact on the mean pain intensity, mean functional interference level, and the proportion of patients who reported pain in the last $24 \mathrm{~h}$ (93\% in Survey 1 vs. $87.3 \%$ in Survey 3), the proportion of patients who reported pain in the last $24 \mathrm{~h}$ at the end of intervention was still high when compared with the results of prior prevalence studies in a German teaching hospital (63\%) [14], and in Chicago, USA (59\%) [38]. Even though the proportion of patients regularly assessed for pain and treated with anti-pain medication through different routes significantly increased, the findings of the current study imply that a larger number of patients still suffer from manageable pain. This could be due to limitations on the availability of anti-pain medication. There is also a possibility that increased attention to pain management from nurses may have given the patients higher expectations towards pain relief and thereby impacted patient responses to Surveys 2 and 3.

The commonly-used pain medications in the study hospital were tramadol, Non-Steroidal Anti-Inflammatory Drugs (NSAID) (paracetamol, ibuprofen, diclofenac, indomethacin), and, rarely, pethidine. However, morphine, the gold standard indicator of adequate pain management, was either not regularly available or not appropriately used. The explanation of medication choice may be linked to various reasons. Those patients who came from districts where community-based health insurance was established and was legally allowed to receive healthcare services free of charge (the poor, pregnant mothers) automatically received all available pain medications in the hospital. However, patients outside this category paid out of pocket. In addition to pharmacological agents, some patients also used nonpharmacological interventions such as massage, prayer, or hot or cold application. On the other hand, the fact that the average monthly income of patients was just over one US dollar per day means that many patients who pay out of pocket may not be able to afford medication or get the medication in a timely fashion. Another possible reason could be the nature of pain. Acute pain is a protective warning signal indicating inflammatory or traumatic tissue damage, whereas chronic pain is a disease per se [2]. Thus, the patient may be in unnoticed acute pain due to missed visits or inadequately managed chronic pain at the time of data collection. However, these situations were the same in the three observation periods.

In a complex intervention that consists of an educational programme and rounding, it is difficult to attribute the contribution of each specific component to the final results [39]. The educational programme improved nurses' knowledge of and attitudes towards pain [25] and was a cornerstone for an evidence-based pain management practice. This could inspire individual nurses to practice proper pain management. Thus, the findings from the second survey, which occurred after the educational programme, could be related to these changes in pain intensity except for average pain in the last $24 \mathrm{~h}$. Rounding, on the other hand, further improved pain treatment by systemizing nurses' care delivery practices in pain management routines. Hence, changes in pain intensity and interference in the final survey are most likely due to the combined effect of both the educational program and rounding. Within the scope of this study, we could only determine the impact of the entire intervention against the baseline result for patient-reported 
pain intensity and functional interference, though these findings must be taken with caution. The educational components of the nurse-based pain management programme upgraded nurses' understanding of pain management, which seemed to help them carry out pain assessments, align analgesics to pain severity levels and monitor patient responses to treatment more confidently. Rounding in this program helped nurses apply their knowledge by organizing pain management practices so that patients were assessed regularly and treated for pain based on the WHO pain ladder.

\section{Strengths and limitations}

The current findings indicate the potential benefits of a nurse-based pain management programme (in-service educational programme and rounding) for hospitalized patients. However, several factors may limit the findings of the current study. One limitation could be attributed to the study design, the use of a non-randomized design without a control group. Initially, we planned to employ a quasi-experimental design with a control group. This was however complicated by a period of public unrest followed by a declaration of a state of emergency, which made it impossible to travel between the intervention and control sites, and our plans to use a control group had to be abandoned. Another limitation is the possibility that nurses may have gained additional knowledge by interacting with medical professionals, thereby improving their practices, resulting in the possibility of physician-initiated pain treatment rather than nurse-initiated pain treatment through consultation. Given all these factors, a simple pre-post study design with three measurement points on separate samples is inadequate for causal inference. Further randomized, multicenter studies are necessary before attributing a nurse-based pain management programme to changes in patient-reported pain intensity and interference. Even though we have no data on the duration of hospitalization or types of procedures the patients had undergone during their hospital stays, it should be noted that this might have influenced the severity of pain.

\section{Conclusion}

The current study provides empirical evidence that a nurse-based pain management programme (in-service education and rounding) significantly improved patientreported pain intensity and interference. The instruments used in this survey could be used for monitoring pain management practices at regular intervals to ensure that the changes are sustainable. The findings also imply the need for educational programmes to improve nurses' technical capacity in in-hospital nursing care. In addition, the phased intervention approach we have used in this study can easily be applied to nursing practices other than pain management, to improve patient-reported outcomes.

\section{Abbreviations}

ANOVA: Analysis of Variances; APS: American Pain Society; APS-POQR: American Pain Society Pain Outcome Questionnaire-Revised; BPI: Brief Pain Inventory; FMoH: Ethiopia's Federal Ministry of Health; IM: Intramuscular; IV: Intravenous; JCAHO: Joint Commission on Accreditation of Healthcare Organizations; JUMC: Jimma University Medical Center; NRS: Numerical Rating Scale; NSAID: Non-Steroidal Anti-Inflammatory Drug; SD: Standard Deviation; SPSS: Statistical Package for the Social Sciences; WHO: World Health Organization

\section{Acknowledgements \\ The authors would like to acknowledge the nurses, nurse unit managers, and the medical center administrators for their support of this research. \\ Ethics approval and consent to participate \\ The study has been notified and approved by the Norwegian Centre for Research Data - project number 48349. Before the commencement of data collection, ethical approval was sought from the institutional review board of the College of Health Science of JUMC, and administrative permission was also obtained from JUMC. During data collection, written informed consent was obtained from each participant.}

\section{Authors' contribution}

All authors have made substantial contributions to this manuscript. GG contributed to the conception and drafted the article. IS and RH critically revised the article for important intellectual content. All authors contributed to the statistical analysis, the design of the study including fieldwork preparation, and the article revision as well as read and approved the submitted version.

\section{Funding}

This work was supported by NORAD (Norwegian Agency for Development Cooperation) under the NORHED programme (grant agreement no. ETH-13/ 0024). This funding body was not involved or had any role in the design of the study, collection, analysis, interpretation of data, and in writing the manuscript.

\section{Availability of data materials}

Due to the NSD's (Norwegian Centre for Research Data) policy, data from this research will not be shared to ensure data confidentiality but can be made available based on official request.

\section{Consent for publication}

Not applicable.

\section{Competing interests}

The authors declare that they have no competing interests.

\section{Author details}

${ }^{1}$ School of Nursing and Midwifery, Jimma University Institute of Health Sciences, Jimma University, 378 Jimma, Ethiopia. ²Department of Nursing Sciences Institute of Health and Society Faculty of Medicine, University of Oslo, Oslo, Norway. ${ }^{3}$ Division of Health Services, Norwegian Institute of Public Health, Oslo, Norway.

Received: 4 February 2019 Accepted: 1 August 2019

Published online: 04 September 2019

\section{References}

1. Woo A, Lechner B, Fu T, Wong CS, Chiu N, Lam H, et al. Cut points for mild, moderate, and severe pain among cancer and non-cancer patients: a literature review. Annals of Palliative Medicine. 2015:4(4):176-83.

2. Ribeiro SBF, Pinto JCP, Ribeiro JB, Felix MMS, Barroso SM, Oliveira LF, et al. Pain management at inpatient wards of a university hospital. Rev Bras Anestesiol. 2012;62(5):605-11.

3. Wang W-Y, Ho S-T, Wu S-L, Chu C-M, Sung C-S, Wang K-Y, et al. Trends in Clinically significant pain prevalence among hospitalized cancer patients at an academic hospital in Taiwan: A retrospective cohort study. Medicine. 2016;95(1):e2099.

4. Alaloul F, William K, Meyers J, Jones K, Logsdon MC. Impact of a scriptbased communication intervention on patient satisfaction with pain management. Pain Manag Nurs. 2015;16(3):321-7. 
5. Institute of Medicine (IOM). Relieving Pain in America: A Blueprint for Transforming Prevention, Care, Education, and Research;2011.

6. Human Right Watch (HRW). Global State of Pain Treatment;2011.

7. Borys M, Zyzak K, Hanych A, Domagał M, Gałkin P, Gałaszkiewicz K, et al. Survey of postoperative pain control in different types of hospitals: a multicenter observational study. BMC Anesthesiol. 2018;18:83. https://doi. org/10.1186/s12871-018-0551-3

8. Gordon DB, Dahl JL, Miaskowski C, McCarberg B, Todd KH, Paice JA, et al. American pain society recommendations for improving the quality of acute and cancer pain management: American pain society quality of care task force. Arch Intern Med. 2005:165(14):1574-80.

9. The Ethiopian Public Health Association (EPHA). Baseline evaluation of pain management practices and teaching in health facilities and health training schools in Ethiopia;2011.

10. Woldehaimanot TE, Eshetie TC, Kerie MW. Postoperative Pain Management among Surgically Treated Patients in an Ethiopian Hospital. PLoS One. 2014; 9(7).

11. Ethiopia's Federal Ministry of Health. Pain management guideline;2007.

12. Tomaszek L, Dębska G. Knowledge, compliance with good clinical practices and barriers to effective control of postoperative pain among nurses from hospitals with and without a "hospital without pain" certificate. J Clin Nurs. 2018;27(7-8):1641-52.

13. Mędrzycka-Dąbrowska WA, Dąbrowski S, Basiński A, Pilch D. Perception of barriers to postoperative pain management in elderly patients in polish hospitals with and without a "hospital without pain" certificate - a multicenter study. Arch Med Sci. 2016;12(4):808-18.

14. Strohbuecker B, Mayer H, Evers GC, Sabatowski R. Pain prevalence in hospitalized patients in a German university teaching hospital. J Pain Symptom Manag. 2005;29(5):498-506.

15. Gianni W, Madaio R, Di Cioccio L, D'Amico F, Policicchio D, Postacchini D, et al. Prevalence of pain in elderly hospitalized patients. Arch Gerontol Geriatr. 2010;51(3):273-6.

16. Witkop M, Lambing A, Fritz R. Prevalence of pain. National Hemophilia Foundation. Nursing Working Group. Nurses' Guide to Bleeding Disorders. 2012. p.1-35.

17. Zhang C-H, Hsu L, Zou B-R, Li J-F, Wang H-Y, Huang J. Effects of a pain education program on nurses' pain knowledge, attitudes and pain assessment practices in China. J Pain Symptom Manag. 2008;36(6):616-27.

18. Simpson K, Kautzman L, Dodd S. The effects of a pain management education program on the knowledge level and attitudes of clinical staff. Pain Manag Nurs. 2002;3(3):87-93.

19. de Rond ME, de Wit R, van Dam FS, van Campen BTM, den Hartog YM, Klievink RM. A pain monitoring program for nurses: effects on nurses'pain knowledge and attitude. J Pain Symptom Manag. 2000;19(6):457-67.

20. Abdalrahim MS, Majali SA, Stomberg MW, Bergbom I. The effect of postoperative pain management program on improving nurses' knowledge and attitudes toward pain. Nurse Educ Pract. 2011;11(4):250-5.

21. Selbst SM, Clark M. Analgesic use in the emergency department. Ann Emerg Med. 1990;19(9):1010-3.

22. Leslie A, Marlow N. Non-pharmacological pain relief. Semin Fetal Neonatal Med; Elsevier. 2006;11(4):246-50. https://doi.org/10.1016/j.siny.2006.02.005.

23. Budh CN, Lundeberg T. Non-pharmacological pain-relieving therapies in individuals with spinal cord injury: a patient perspective. Complement Ther Med. 2004;12(4):189-97.

24. Wells-Federman C, Arnstein P, Caudill M. Nurse-led pain management program: effect on self-efficacy, pain intensity, pain-related disability, and depressive symptoms in chronic pain patients. Pain Manag Nurs. 2002;3(4): $131-40$.

25. Germossa GN, Sjetne IS, Hellesø R. The Impact of an In-service Educational Program on Nurses' Knowledge and Attitudes Regarding Pain Management in an Ethiopian University Hospital. Front Public Health. 2018;20(6):229.

26. World Health Organization (WHO). WHO Normative Guidelines on Pain Management. Geneva: Report; 2007.

27. World Health Organization (WHO). WHO guidelines on the pharmacological treatment of persisting pain in children with medical illnesses;2012.

28. Hutchings M. Caring around the clock: rounding in practice. Nurs Times. 2012;108(49):12-4

29. Hanley MA, Masedo A, Jensen MP, Cardenas D, Turner JA. Pain interference in persons with spinal cord injury: classification of mild, moderate, and severe pain. J Pain. 2006:7(2):129-33.4
30. Keller S, Bann CM, Dodd SL, Schein J, Mendoza TR, Cleeland CS. Validity of the brief pain inventory for use in documenting the outcomes of patients with noncancer pain. Clin J Pain. 2004;20(5):309-18.

31. Gordon DB, Polomano RC, Pellino TA, Turk DC, McCracken LM, Sherwood G, et al. Revised American pain society patient outcome questionnaire (APSPOQ-R) for quality improvement of pain management in hospitalized adults: preliminary psychometric evaluation. J Pain. 2010;11(11):1172-86.

32. Beatty PC, Willis GB. Research synthesis: the practice of cognitive interviewing. Public Opin Q. 2007;71(2):287-311.

33. Woldehaimanot TE, Saketa YJ, Mulatu A, Zeleke HA, Woldeyohanes TR. Pain knowledge and attitude: a survey among nurses in 23 health institutions in Western Ethiopia. Gazi Med J. 2014;20(3):254-60

34. Sepúlveda C, Marlin A, Yoshida T, Ullrich A. Palliative care: the World Health Organization's global perspective. J Pain Symptom Manag. 2002;24(2):91-6.

35. Berry $\mathrm{PH}, \mathrm{Dahl} \mathrm{JL}$. The new joint commission on accreditation of healthcare organization (JCAHO) pain standards: implications for pain management nurses. Pain Manag Nurs. 2000;1(1):3-12.

36. Wells N. Pain intensity and pain interference in hospitalized patients with cancer (abstract). Oncology Nursing Forum; 2000.

37. Max MB, Donovan M, Miaskowski CA, Ward SE, Gordon D, Bookbinder M, et al. Quality improvement guidelines for the treatment of acute pain and cancer pain. Jama. 1995:274(23):1874-80.

38. Whelan CT, Jin L, Meltzer D. Pain and satisfaction with pain control in hospitalized medical patients: no such thing as low risk. Arch Intern Med. 2004;164(2):175-80.

39. Richards DA. The complex interventions framework. In: Richards DA, Hallberg IR. (Eds.). Complex interventions in health. An overview of research methods. 1st ed. London: Routledge; 2015.

\section{Publisher's Note}

Springer Nature remains neutral with regard to jurisdictional claims in published maps and institutional affiliations.

Ready to submit your research? Choose BMC and benefit from:

- fast, convenient online submission

- thorough peer review by experienced researchers in your field

- rapid publication on acceptance

- support for research data, including large and complex data types

- gold Open Access which fosters wider collaboration and increased citations

- maximum visibility for your research: over $100 \mathrm{M}$ website views per year

At $\mathrm{BMC}$, research is always in progress.

Learn more biomedcentral.com/submissions 